\title{
The Harrison Lecture, 1976 Sexually transmitted diseases (STD) as a medical specialty
}

\author{
THOMAS B. TURNER \\ The fohns Hopkins University School of Medicine, Baltimore, Maryland, U.S.A.
}

It is a very special honour to give the second Harrison Lecture; and personally gratifying, though somewhat awesome, to follow that skilled clinician, scholar, and friend-Ambrose King.

Colonel L. W. Harrison stands tall in the history of the sexually transmitted diseases (STDs), as he did in life. After his outstanding services to the Armed Forces of Great Britain in World War I, he returned to England to organize a civilian service that brought effective venereal disease treatment to those cases of infection most difficult to discover. In an era before the National Health Service, he made it possible for one group of patients to have ready access to good medical care under conditions of dignity and privacy. Ambrose King, in the first Harrison Lecture, has given a full and most interesting account of the venereal disease service in Great Britain as it evolved under Col. Harrison's leadership (King, 1974).

About 1928 Col. Harrison travelled to North America, visiting The Johns Hopkins University School of Medicine among many other medical centres, where I, as a young beginner in the field, met this impressive man who spoke persuasively of the things about which he felt so strongly. In retrospect, this trip had momentous consequences for he explained to knowledgeable listeners across the land the need to implement aggressive measures to bring persons with venereal disease under medical care where diagnosis could be made, treatment instituted, and spread of infection checked. I have been unable to document the direct personal influence that Col. Harrison had on Thomas Parran, who was chiefly responsible for lifting syphilis from the shadows in America (Parran, 1937). There is no doubt that Parran was extremely impressed with the venereal disease service of the British Ministry of Health and gained enormous moral support from Col. Harrison for his own pioneering efforts in the effective treatment of sexually transmitted diseases in America.

Delivered on March 24, 1976, to the MSSVD

Address for reprints: Dr Thomas B. Turner, M.D., The Johns Hopkins University School of Medicine, Baltimore, Maryland 21205, U.S.A.
The Ministry of Health has been wise in the selection of physicians as technical directors of its venereal disease service, and fortunate in the human and professional qualities of the incumbents-only four since the service began 60 years ago. (It is pleasant for me to recall that $I$ have known and admired them all, including the two who are with us this evening-Ambrose King and Claude Nicol.)

\section{Notes from the past}

It has been one year short of a half century, since largely through chance my career became inextricably associated with the treponemal diseases. My preoccupation with these diseases has governed much of my research, travels, and friendships.

For me, the quest for understanding the interaction between the $T$. pallidum and the human host has been the small but intense beam of light that has helped to illuminate the whole of medicine. Under the darkfield microscope the treponeme itself-a white, shimmering spiral form of microscopic life-has a certain beauty and commands a reluctant respect because of its power to wreck a human mind or body.

On the other side of the equation is man. What reactions to the treponeme occur at the cellular level, and what are the effects on the whole person? How do these in turn affect the invading organism ? In yet another dimension, one asks what kinds of human beings are affected, how many, where, and under what circumstances are they most at risk? What traits of character, what social systems, what economic situations are most conducive to spread of the several treponematoses? What are the effects of the physical environment on both host and parasite? And, finally, what can the perspectives of history tell us?

To comprehend such questions, one must explore countless avenues of human knowledge, too many to be grasped by anyone in depth. Yet in retrospect, I would not have foregone the personal pleasure of the longTvigils at the darkfield microscope, the special satisfactions of dealing with patients, the hours in the British Museum reading the eye-witness accounts of 
the white man's first forays ashore in equatorial Africa decades before Columbus discovered America, and the field work to find modes of spread of several treponematoses. I have attempted to bring it all together in the chapter on 'Syphilis and the Treponematoses' in a book edited by Stuart Mudd (Turner, 1970).

\section{The rise of specialism in the venereal diseases} Specialism in medicine arises principally when advancement in knowledge and the development of new technology require special skills for their application to the prevention, diagnosis, or treatment of disease. Thus, in the first decade of this century, development of the first serological tests for syphilis, the old Wassermann test, and Ehrlich's 'magic bullet' Salvarsan posed formidable technical problems well beyond the understanding of the general practitioner. In consequence, a small but dedicated and closely knit specialty emerged in all the medically developed countries.

In the United Kingdom momentum was given the idea of specialization by the venereal disease service of the Ministry of Health inaugurated in 1917. The regulations specified that, to receive government grants, venereal disease clinics had to be under the direction of physicians qualified by special training and skill in the treatment of these diseases.

In the United States a few specialist university centres started shortly after Salvarsan became available. Probably because of the direction taken at The Johns Hopkins University Medical School, interest concentrated on syphilis to the virtual exclusion of the other venereal diseases. At this medical school development was sparked by a remarkable man whose name has been submerged in the context of the venereal diseases. George Walker, a dynamic farseeing individual, was a surgeon by training. In 1914, while chief of the surgical outpatient clinic at The Johns Hopkins Medical School, he conceived the idea of a specialty group devoted to the treatment and study of syphilis. He persuaded Mr. John D. Rockefeller, Jr., to support the project with a 3-year grant and recruited Albert Keidel as his assistant. In the first year 700 patients were treated and 5,000 Wassermann serum tests performed.

In 1921, the syphilis clinic, initially known as Department L, had become one of five specialty divisions within an expanded Department of Medicine which was emphasizing clinical investigation. The other divisions covered cardiovascular disease, metabolic disease, general infectious diseases, and tuberculosis. Alan M. Chesney joined the Syphilis Division to develop laboratory investigations and became co-director with Keidel of the clinic. Another new recruit was J. Earle Moore.

The point of this detail is that syphilis was hence- forth regarded at Johns Hopkins as one of the components of internal medicine. But beyond that, extraordinary developments occurred through the joint influences of Moore and Chesney. For over 30 years after its inception the Syphilis Division had a major national and international impact in patient care, teaching, and clinical and laboratory research (Turner, 1974).

Among the unique features of Department $L$, later designated Medicine I, was its thoroughgoing approach to the management of syphilis as befitted trainee specialists in internal medicine. The result of this clinical approach to syphilis was that in general the staff of Medicine I felt competent to manage all but the most complicated medical problems, and the clinic was in the mainstream of medical student teaching.

Another early and unique development was the emphasis on long-term follow-up of patients who had syphilis. This programme concentrated upon those still requiring extensive treatment and those with special types of syphilis providing clinical research interest. Equally important, perhaps, was the practice of other medical staff to refer to Medicine I any patient readmitted to the hospital who had previously been treated at the clinic. There was also the automatic referral to Medicine I of patients, including blood donors, who were discovered in another clinic to have positive serological tests for syphilis.

Four other developments should be briefly noted. In the late 1930s, again largely through Moore's vision, a post-doctoral training course was started in the clinic which I was selected to direct. The course was developed primarily to train physicians who would direct venereal disease control programmes at state and national level. At my insistence these physicians were also instructed in the rudiments of public health by participating in the Master of Public Health degree course at The Johns Hopkins School of Hygiene and Public Health. In the long term this may have been a mistake, but for over two decades some of the top career officers of the U.S. Public Health Service and key state officials participated in this special course.

A second innovation was the inauguration of a 'Family Clinic' based in Medicine I where the whole family could be examined and treated. It was an idea ahead of its time and remains the central idea now underlying the development of primary care centres in America.

A third development, whose place in history is still open to interpretation, is the extraordinary relationship established between the Johns Hopkins clinic and venereologists in Great Britain. Again, Moore's imagination and enormous energy were key factors, but there must have been vitally important factors in this relationship on this side of the Atlantic. 
Finally, a buoyant spirit of research pervaded Medicine I. Research was not a new endeavour at The Johns Hopkins Medical School, yet never before had an outpatient clinic been so heavily utilized as the basis for first-rate clinical investigation. Sparked by Chesney in the laboratory and Moore in the clinic, every member of the department participated in these investigations which attracted many visitors to The Johns Hopkins Medical School.

The more recent history of the Syphilis Division is instructive. In a way its success led to its undoing. Administratively it was part of the Department of Medicine, but its clinical range was limited. When the first exciting years of the penicillin era were over and syphilis rates fell it was thought there was little future for a syphilis clinic. Once Chesney became Dean of the Medical School and Moore's attention turned toward other chronic diseases, the Hopkins clinic slipped into desuetude. It exists today as a useful historical monument-the Moore Clinicdevoted to clinical investigation in such fields as genetics, hypertension, and arthritis.

\section{Leadership returns to Great Britain}

In other American clinics the management of syphilis followed one of two general patterns. It became part of internal medicine as, for example, at Cornell and Vanderbilt universities; or it became the responsibility of dermatologists as at the University of Pennsylvania, Western Reserve, and Baylor University. But it is my belief that the demise of syphilology as an exciting academic field in the United States had less to do with organizational detail than with two other factors. One was the real decline in clinical problems; the other, of great importance, was the decision made by most states and cities, to move syphilis clinics away from university hospitals to health department settings. In medicine we do not teach well those things we do not actually do. There was no likelihood then that meaningful instruction in syphilis could be maintained in our medical schools. In consequence a generation of younger physicians in the United States has no knowledge of the disease.

Noteworthy too is that only in health department settings were syphilis and the other recognized venereal diseases managed in the same clinic. In university hospitals, the clinics tended to be restricted and fractionated.

This has not been the case in Great Britain. The wisdom of placing venereal disease clinics in medical school settings wherever feasible, a decision made 60 years ago, is very important in retrospect. For not only did the clinical base remain wider but the tradition of research, even if sometimes latent, persisted as a vitalizing force. The common denominator was not a single disease, but a group of diseases with clinical, epidemiological, and sociological problems arising mainly from sexual contact. One need scarcely seek a broader base for a clinical specialty and for the development and exercise of special professional skills and judgment.

The evolution of the specialty of the sexually transmitted diseases in Great Britain has confirmed the rationale of this approach and demonstrated the practical demand for such services on the part of both the profession and the public. Growing knowledge has added new insights and new medical approaches in the treatment of the older diseases such as syphilis, gonococcal infections, chancroid, lymphogranuloma venereum (LGV), and granuloma inguinale. Moreover, new syndromes have been recognized which challenge the diagnostic, preventive, and therapeutic skills of the specialists in sexually transmitted diseases: for example, herpes virus infections with their aetiological implications for cervical cancer. Patients with such syndromes now comprise about three-quarters of the total of all patients in STD clinics (Nicol, 1971; Catterall, 1972).

\section{Relation to other medical specialties}

If the present situation is compared with that of 30 years ago, the change in the intellectual content and pertinent technologies is seen to be startling. While the old skills are still needed, they have been superseded to an extent by newer ones that were scarcely imagined a generation ago.

Of course, other and related specialties are changing too, but often in ways which encourage rather than duplicate the development of the STD specialty. Gynaecology, for example, remains largely a surgical specialty although the medical and endocrinological aspects form an integral part of the picture. Similarly, urology is essentially a surgical specialty with its own techniques, demanding skills, and special interests. It is unlikely that either of these groups of specialists will in the long run devote major efforts to the STD diseases, and hence be particularly efficient in their management. The dermatologist fell heir to some of the STD diseases largely through the cutaneous features of secondary syphilis but has never been comfortable in assuming responsibility for the whole gamut of the STDs. Moreover, dermatology is on the threshold of great developments as a clinical science, and deserves the most earnest dedication to problems more clearly identified with its core as a specialty. Again, it seems unlikely that this group of experts would wish to put a major share of their efforts into the specialty of STD.

It seems, therefore, that society in general and medicine in particular needs the STD specialist. As a group these diseases are apparently increasing in frequency. Social changes are conducive to their 
spread, and other factors may be increasing the rate of infection. Moreover, the upper socio-economic classes of society are being invaded to a much greater degree than was observed in the past.

\section{Future prospects}

Let us now look to the future. First, what can be visualized as the natural evolution of STD as a specialty? It is unlikely to remain static, but will evolve in relation to its own inherent medical and sociological problems and, it should be emphasized, in relation to the evolution of other medical disciplines. I have already mentioned gynaecology and urology and the likelihood that specialists in these disciplines welcome a group of colleagues to whom they can refer diagnostic and treatment problem-cases of an STD nature. The same will probably hold true for other specialists in internal medicine and for the primary care physician.

But I also foresee another possible development. There are growing indications that psychiatry, at least as it has been known in America in the past three decades, is in some disarray (Torrey, 1974; Brown, 1976). The specialty deals more and more with elusive and ill-defined clinical syndromes for which there are often no clear diagnostic criteria or specific therapeutic measures. The psychiatrist is in troubled waters, not because he is not needed, but because persons trained in peripheral disciplines, psychology, for example, can often deal in an equally effective manner with many mental disorders. It may be, therefore, that in the complex field of sexuality the physician who has knowledge and technologies to deal with the somatic aspects of sex in its narrower sense could well develop complementary skills embracing the psychological and sociological aspects. While STD specialists may not possess a unique key to the sexual problems that beset men and women, they are at least in a position to recognize the significant somatic factors that may be involved, and therefore have a more balanced judgment concerning the role of psychological elements that bear upon the problem. In America today, men and women are obtaining advice, in many instances probably good advice, on sexual matters from professionals and semi-professionals who possess various kinds of basic training. It may be that his training and experience will enable the STD specialist to develop superior competence in this area of medicine. A somewhat similar suggestion has been made by Saoji, Chaudhari, and Saoji (1973).

\section{Importance of research}

Finally, I wish to comment on a matter of vital importance to any specialty. The specialist has usually arrived at his position in the field by knowing more about the subject than his colleagues. He will maintain this leadership only by acquiring pertinent new knowledge more consistently than others; in short, through research. No specialty can survive without it; no specialist should wish to carry on free of its influence. This applies as much to the STD specialist as to any other. Research is much broader than laboratory, clinical, or epidemiological investigations. Research is the 'spirit of inquiry'; the intelligent questioning of accepted views; the willingness to keep an open mind; the observation of events as though they were new, and the search for relationships that exist beyond mere chance. On the one hand the richness of medicine flows from its concern for human beings and the privilege to search for the secrets of health and disease; and on the other, from the need to bring the discoveries in any field of knowledge to focus on a particular problem of human biology.

One of the prime functions of the Medical Society for the Study of Venereal Diseases should be to encourage research in this field. It was my privilege to participate last year in the Anglo-American Conference on Sexually Transmitted Diseases held in London. The proceedings of that meeting are rich in implied opportunities for the future (Turner, 1976). The splendid accomplishments of the past, even the recent past, carry great promise for the future. Yet this promise will not be realized unless a few gifted individuals have the inspiration, the incentive, the knowledge, and the opportunity to pursue some of the many questions that face this special field of medicine. The same holds true for all the sexually transmitted diseases.

It is in the universities of the world, and especially in the medical schools, where the spirit of inquiry flourishes best, and so I refer again to Col. Harrison's wise decision to place the original venereal disease clinics primarily within the great medical centres of the United Kingdom. There they can benefit from the academic environment, where the three great complementary activities of medicine come together in harmony: patient care, teaching, and research.

\section{Conclusion}

It is clear that in the Western World leadership in the broad field of sexually transmitted diseases has become centred in the United Kingdom. A recognized medical specialty is in existence; a viable professional society, the Medical Society for the Study of Venereal Diseases, provides a means of communication among practitioners and others interested in the field; and the British Fournal of Venereal Diseases remains one of the outstanding publications of its kind. Abstracts on Hygiene should receive special mention, too, for its annual 'Perspectives in Venereology'.

Leadership is usually attained by merit and retained 
by merit. Leadership entails responsibility, continuing effort, the flexibility to change with the growth of knowledge, and a vision that sees beyond the horizon. The situation in the United Kingdom looks propitious.

\section{References}

Brown, B. S. (1976) Amer. F. Psychiat., 133, 489 Catterall, R. D. (1972) Lancet, 2, 321

KIng, A. (1974) Brit. F. vener. Dis., 50, 391

Nicol, C. S. (1971) Brit. med. f., 2, 448, 507
Parran, T. (1937) 'The Shadow on the Land', p. 309. Reynal and Hitchcock, New York

SaOjI, N. J., Chaudhari, V. D., and SaOjI, A. (1973) $\mathcal{f}$. Indian med. Ass., 60, 391

TORREY, E. F. (1974) 'The Death of Psychiatry', p. 234. Chilton Book Co.

TURNER, T. B. (1970) 'Syphilis and the Treponematoses' in 'Infectious Agents and Host Reactions', ed. S. Mudd, p. 346. Saunders, Philadelphia

(1974) 'Heritage of Excellence-The Johns Hopkins Medical Institutions, 1914-47'. Johns Hopkins Press, Baltimore

(1976) 'Future direction of research into syphilis', Proc. Anglo-Amer. Conf. on S.T.D., London (in press) 